WEATHER CONDITIONS AT THE SHARON SANATORIUM.

BY WALTER A. GRIFFIN, M.D., SHARON,

Resident Physician at the Sharon Sanatorium, Sharon, Mass.

These observations were taken at the Sharon Sanatorium, an institution for the treatment of incipient pulmonary tuberculosis. It is situated about eighteen miles from Boston at an elevation of some 250 feet above the sea. This report is not intended to prove that the weather conditions at the Sanatorium are ideal, but they may be taken in connection with the results of treatment of tuberculosis at this institution, as shown in the annual reports and in various papers by Dr. Bowditch, to indicate how much may be accomplished in a climate not naturally favored, provided the patients are given the right sort of regimen.

A record of the amount of sunshine has been kept for three years. The data were collected for half that time by the nurses at the Sanatorium, and for the rest of the time by the author. The fact that there has been but little variation in the amount recorded in the whole time argues something for the method of making the data, by personal observation. There has been an average of 168 days each year when the sun shone all day, and 85 days when there was no sun. The other 112 days of the year had sun for one fourth of the time or longer, and these various fractions of sunny days have amounted on an average to the equivalent of 65 whole days of sunshine per year. . These added to the 168 days already mentioned would make an average of 223 sunny days each year. Such a grouping seems fair since many of the days sunny only in part are really as pleasant as those on which the sun shines all the time. How the amount of sun was distributed each year is shown by the following table:

\begin{tabular}{|c|c|c|c|c|}
\hline & $\begin{array}{l}\text { Sun all } \\
\text { day. }\end{array}$ & $\begin{array}{l}\text { Total sum of } \\
\text { sunny days. }\end{array}$ & $\begin{array}{l}\text { Per cent of } \\
\text { sunny days. }\end{array}$ & $\begin{array}{l}\text { Days entirely } \\
\text { without sun. }\end{array}$ \\
\hline & 163 & 224 & 61 & 86 \\
\hline & 172 & 221 & 62 & 87 \\
\hline 19 & 170 & 224 & 61 & 83 \\
\hline
\end{tabular}

The amount of sun does not vary in different months as much as might be expected. The average by months for the three years follows:

$\begin{array}{lccc}\text { Month. } & \begin{array}{c}\text { Total amount } \\ \text { of sun. }\end{array} & \begin{array}{c}\text { Per cent. } \\ \text { Jan. }\end{array} & \begin{array}{c}\text { Days entirely } \\ \text { without sin. }\end{array} \\ \text { Feb. } & 18 & 58 & 9 \\ \text { March } & 17 & 64 & 8 \\ \text { April } & 18.5 & 55 & 13 \\ \text { May } & 22 & 62 & 7 \\ \text { June } & 18.5 & 62.4 & 4 \\ \text { July } & 20 & 64.5 & 7 \\ \text { Aug. } & 18.5 & 60.2 & 4 \\ \text { Sept. } & 20 & 66.6 & 4 \\ \text { Oct. } & 17.8 & 57.5 & 9 \\ \text { Nov. } & 18.5 & 62 & 7 \\ \text { Dec. } & 15.7 & 50.8 & 9\end{array}$

About a year and a half ago maximum and minimum thermometers and a rain gauge were set up. A sling psychrometer was also bought. This instrument consists of a wet and a dry bulb thermometer from the reading of which may be computed, with the aid of tables furnished by the government, the vapor pressure, relative humidity and temperature of the dew point. Records have been taken once a day, as near 8 A.M. as possible.

The average mean temperature in the year and a half has been 46.5 degrees. The highest record was in July, 1903, when 94 was reached. Only three times has the thermometer registered above $90^{\circ}$. The lowest temperature was $14^{\circ}$ below zero.

The relative humidity has been high as one would expect from the nearness to the New England coast. It has been above $90^{\circ}$ about six times each month. It rarely goes below $35 \%$, and averages $73 \%$. There has been but slight differences in different months. The absolute humidity has not been worked out.

The rainfall was 41.7 inches for 1904 and 16 inches for the last six months of 1903 . It is to be noted that rarely is there less than 2 inches in a month. Because of the gravelly nature of the soil surface water is quickly taken up. How the temperature, humidity and precipitation have varied by months is shown by the following table:

$\begin{array}{lccccc}\text { Month. } & \begin{array}{c}\text { Highest } \\ \text { 19mp. }\end{array} & \begin{array}{c}\text { Lowest } \\ \text { temp. }\end{array} & \begin{array}{c}\text { Average mean } \\ \text { temp. }\end{array} & \begin{array}{c}\text { Av. relative } \\ \text { humidity. }\end{array} & \begin{array}{c}\text { Precipi- } \\ \text { tation. }\end{array} \\ \text { July } & 94 & 49 & 70 & & 2.52 \\ \text { Aug. } & 84 & 44 & 62 & 79 & 3.49 \\ \text { Sept. } & 87 & 35 & 62 & 78 & 1.27 \\ \text { Oct. } & 75 & 22 & 51 & 79 & 4.26 \\ \text { Nov. } & 70 & 5 & 37 & 76 & 1.32 \\ \text { Dec. } & 53 & -8 & 25 & 71 & 3.25 \\ \text { 1904 } & 46 & -14 & 12 & 78 & 4.60 \\ \text { Jan. } & 46 & -8 & 20 & 72 & 3 \\ \text { Feb. } & 49 & -7 & 32 & 66 & 3 \\ \text { Mar. } & 68 & 0 & 43 & 68 & 8.62 \\ \text { April } & 72 & 12 & 43 & 65 & 2.66 \\ \text { May } & 85 & 32 & 58 & 73 & 1.97 \\ \text { June } & 92 & 35 & 61 & 79 & 2.51 \\ \text { July } & 88 & 43 & 72 & 79 \\ \text { Aug. } & 88 & 45 & 66 & 74 & 2.35 \\ \text { Sept. } & 85 & 27 & 60 & 77 & 6.22 \\ \text { Oct. } & 79 & 18 & 48 & 73 & 2.68 \\ \text { Nov. } & 58 & 8 & 32 & 74 & 1.39 \\ \text { Dec. } & 52 & 0 & 22 & 67 & 2.71\end{array}$

No record has been made of the direction or velocity of the wind, but in general all west winds are fair and east winds bring foul weather. Sudden changes are frequent, but the harshness of the east wind is not felt so keenly as in Boston because of the intervention of the Blue Hill of Milton. The Sanatorium is so well protected by woods that there is seldom any hardship to patients from winter winds.

\section{A SUGGESTION FOR A PRACTICAL APPARATUS FOR USE IN INTRA-THORACIC OPERATIONS.*}

BY FRED T. MURPHT, M.D., BOBTON.

SiNCE the field of intra-thoracic surgery seems to offer so great opportunities for work, and since with a suitable apparatus all danger of collapse of the lungs can be eliminated, I present the

* I am much indebted to Drs. W. B. Cannon, F. E. Garland and B. Vincent for their assistance in this work. 
following suggestion for a simple and practical method was devised to insure normal respiraapparatus for use in intra-thoracic operations.

Surgical operations within the thoracic cavity have been comparatively rare except for empyema, and this in a great measure is so because of the possibility of a dangerous collapse of the lungs when the pleural cavity is opened. That a single pleural cavity sometimes may be opened without causing alarming dyspnea is proven by numerous reports of cases, yet the danger from this complication is imminent.

tion during intrathoracic operations on the human being until Sauerbruch published the description of his " negative or minus pressure" chamber.

The essential feature of his method is to maintain a minus pressure over the exposed lung equal to the normal interpleural pressure, that is, about $10 \mathrm{~mm}$. of mercury. This was done by Collapse of the non-adherent lung on opening a in which the operator stands and in which by single pleural cavity has been prevented in various means of suction pumps the air is constantly ways, $e$. $g$., by allowing the pneumothorax to renewed and kept at the required minus pressure. occur slowly, by the preliminary formation of This original chamber has been modified so that adhesions between the visceral and parietal the abdomen and lower extremities are not

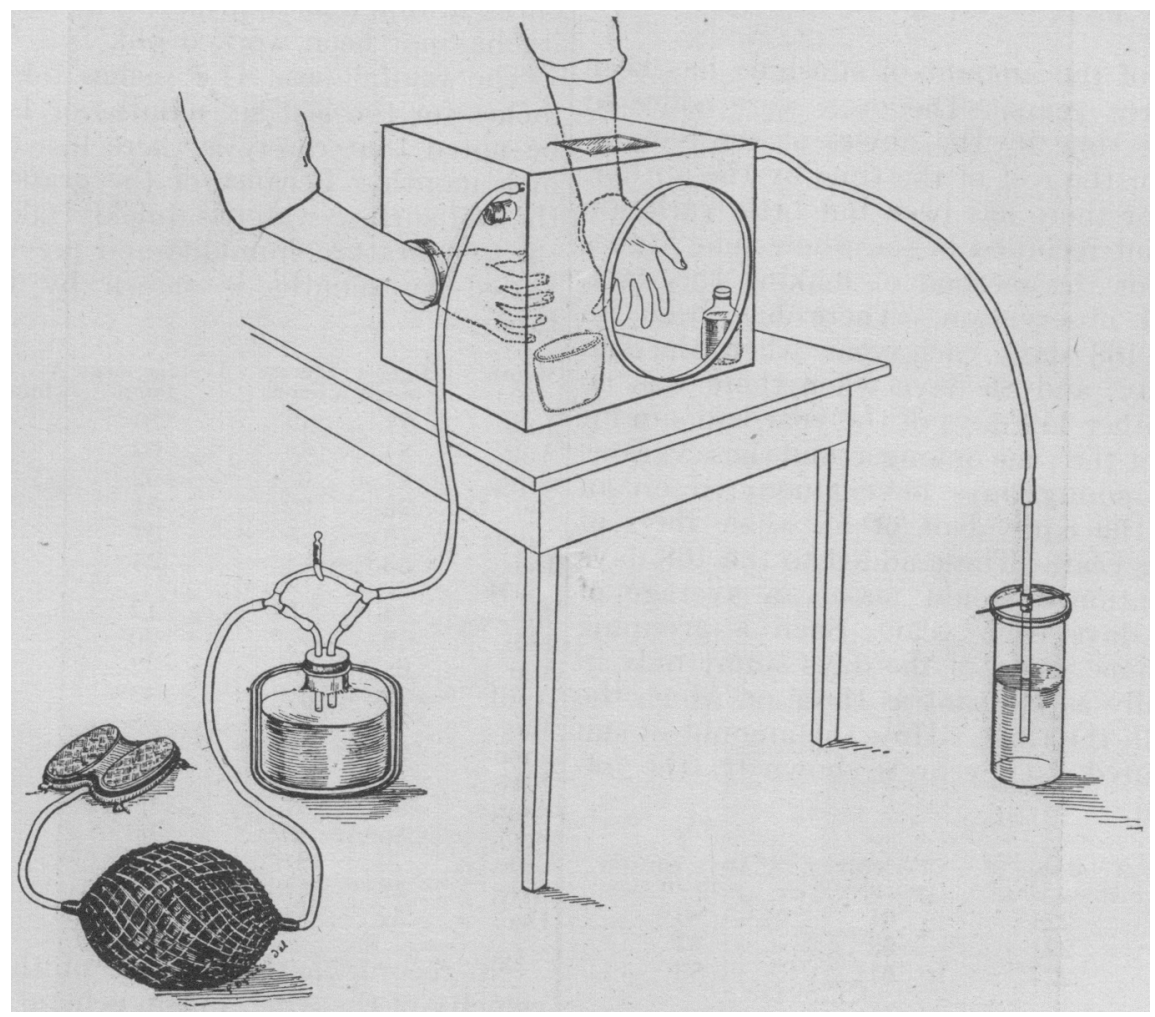

FIG. 1.

pleura, by stitching the lung to the chest wall / subjected to the minus pressure. Animal exand by seizing the lung when the pleural cavity periments and operations upon the human being is opened and holding it so that the mediastinal have demonstrated the practicability of the partition is kept in place and the opening in the chest wall kept closed. No one of these methods has proven entirely satisfactory for the free exploration of the pleural cavity.

If a double pneumothorax is created by breaking through the mediastinal partition, as would happen in extensive operations on the thoracic portion of the esophagus, there must be a practically immediate and fatal collapse unless by some artificial means the lungs are inflated. Physiologists have long used artificial respiration in animal experiments by means of a tracheotomy tube and a rhythmically acting air pump. The FellO'Dwyer apparatus may tide over an emergency collapse of the lung, but no satisfactory working above-described method.

Braurer and Petersen reversed the method of Sauerbruch and employed a plus pressure within the lungs instead of a minus pressure without. They introduced air into the lungs from a reservoir under a constant pressure of about $10 \mathrm{~mm}$. of mercury above the normal atmospheric pressure, either by means of a tracheal canula, or through a chamber which contained the patient's head and the anesthetist, or by means of a small complicated head apparatus which contained the patient's head and the hands of the anesthetist. Engelken and Wilms have suggested technical modifications in the application of this method. Animal experiments and operations 
upon the human being have also demonstrated cabinet. The double valve foot pump for mainthe practicability of this plus pressure method. taining pressure, the rubber reservoir and the

Certain questions as to the relative value of jacketed ether bottle are such as have been used the plus or minus pressure have been raised, and in the Fillebrown apparatus for giving ether in in regard to the plus pressure it has been stated operations about the mouth as described and that acute circulatory disturbances follow its perfected by Mosher and Green. The double use and that there is an alarming loss of body jacket surrounding the ether bottle readily keeps temperature. the ether for forty-five minutes at about $110^{\circ} \mathrm{F}$.

Without entering into a discussion here of the if water of about that temperature is put into the theoretical advantages of the one method over the inner cylinder and much hotter water into the other, I would say that I have employed the plus outer. By the arrangement of the tubes in the pressure method on a considerable number of ether bottle the in-going air from the foot pump

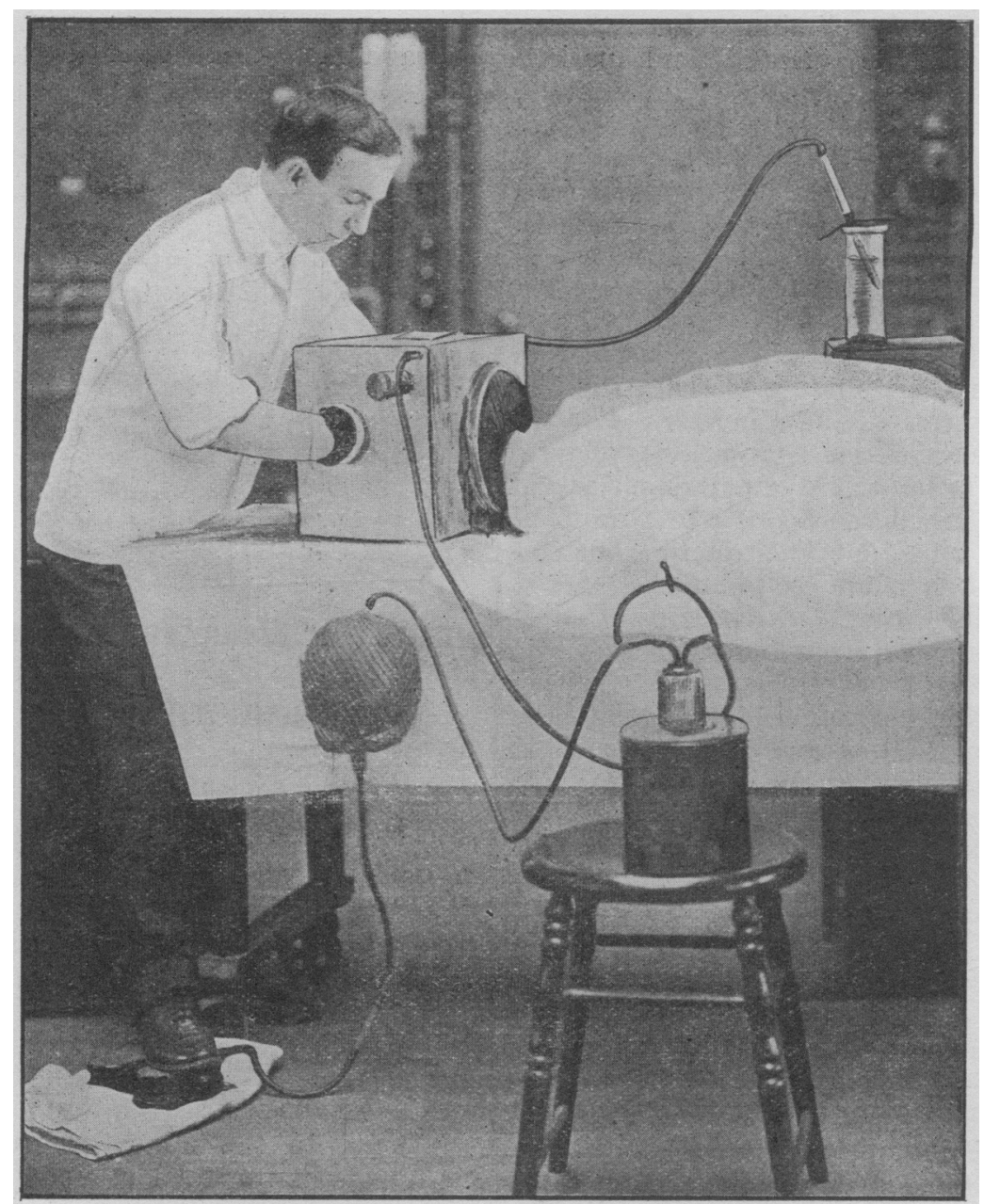

FIG. 2.

animals - the results of which experiments will through the rubber reservoir may be sent wholly be published later - without meeting with any or in part through the ether vapor or may be difficulty either with the circulation or the respi- forced into the cabinet without containing any ration, provided that the pressure was main- ether.

tained at a level of from 8 to $10 \mathrm{~cm}$. of water, The chamber for the head consists of a simple that is about $7 \mathrm{~mm}$. of mercury, and provided that sheet-zinc box, 12 inches high, 15 inches wide in the operating room was kept at somewhere near front and 12 inches behind, and 10 inches deep. body temperature.

In the top is a glass window through which the face

Fig. 1 shows a small cabinet for the head of the of the patient may be watched. At either side is patient and the hands of the anesthetist, an an opening $3 \frac{1}{2}$ inches in diameter surrounded by apparatus by which the plus pressure is main- a strong, lipped flange 1 inch wide. These opentained and the ether given and a water mano- ings at the sides have been placed $3 \frac{1}{2}$ inches from meter for regulating the pressure within the the top and $1 \frac{1}{2}$ inches from the back wall because 
in this position and with the narrower back wall the anesthetist can without difficulty introduce his hands and have perfect control of the patient's head. At either side also is a tube $\frac{1}{2}$ inch in diameter for the inlet and outlet of the air, On the right side is an opening $1 \frac{1}{2}$ inches in diameter which is ordinarily kept closed by a rubber cork. This cork may be removed in case the plus pressure within the chamber is not needed. In the front wall is an opening 9 inches in diameter through which the patient's head is introduced into the chamber. This also is surrounded by a heavy, lipped flange 1 inch wide. This opening is placed 1 inch from the bottom and 2 inches from the left side in order that there may be room to turn the head to the right in case of vomiting.

When the chamber contains the head of the patient and the hands of the anesthetist there is still ample room for an ether bottle and cone so that if there is any difficulty in administering sufficient ether by means of the foot pump or in case the rubber cork has been taken out it is possible to give the ether as if the cabinet were not in place.

Fig. 2 shows the apparatus in working order with rubber cuffs surrounding the neck of the patient and the arms of the etherizer. For the cuff about the neck "dentist's heavy weight" rubber sheeting is used. A circular hole is cut in the sheeting only large enough to admit the patient's head, after gentle stretching of the rubber. The cuff is made secure at the level of the thyroid cartilage by means of strips of adhesive plaster so applied that they come within the chamber when it is in operation. Neither the rubber sheeting nor the adhesive strips need to be tight enough to prevent in the least the superficial venous flow in the neck. This cuff should be arranged before the anesthetic is started. Then when the patient is fully etherized the head is placed within the chamber and by a few turns of long adhesive plaster strips the rubber sheeting is fixed around the lipped flange. The rubber cuffs for the arms may also be made with rubber sheeting, but a 5-inch "band rubber" tube is more easily handled. The cuffs are also fixed with adhesive strips. The material for the head and arm cuffs may be obtained from the Davidson Rubber Company's factory.

The water manometer consists of a glass tube over which is slipped a short piece of rubber tubing, and a vessel sufficiently deep to provide a depth of about $16 \mathrm{~cm}$. of water. The rubber tubing over the glass tube is transfixed by a wire which is long enough to reach across the vessel which contains the water. By moving the rubber tubing up or down the depth to which the glass tube enters the water is varied and so the degree of pressure within the cabinet may be regulated. This pressure, I believe, should be only so much as is in each case necessary to allow a sufficient change of the air within the lungs and is not a fixed amount.

In using the chamber the eyes should be protected by moist compresses because the box is filled with ether vapor. The tongue should be held forward by a stitch so that it cannot be forced against the roof of the mouth by the plus pressure.

Thus far no opportunity has offered to test this apparatus on a human being in whom the pleural cavity was opened, but it has been demonstrated on a well man that with a closed thoracic cavity the pressure within the cabinet can be maintained without effort, with an ample supply of oxygen and without danger of injury to any part of the appliance. A similar apparatus of smaller size has made it possible on animals to open one or both pleural cavities without any apparent disturbance of respiration or circulation and the lungs did not collapse.

If the apparatus works equally well in operations upon human beings it possesses the advantage of cheapness, portability, ease of manipulation and simplicity.

\section{BIBLIOGRAPHY.}

Sauerbruch, F.: Zent. f. Chir., band xxxi, s. 146-149. Brauer und Petersen: Hoppe-Seyler's Zeitschr. f. physiol. Chemie, band 41 , heft 4

Sauerbruch, F.: Mitteilungen aus den Grenzgebieten der Med. u. Chir., band xiii, heft 3.

Brauer, L.: Mitteilungen aus den Grenzgebieten der Med. u. Chir., band xiii, heft 3 .

v. Mikulicz, J.: Deut. Med. Wochenschrift, 1904, hefte 15-16, s. 30 und 577

Engelken, H. J.: Deut. Med. Wochenschrift, 1904, heft 51.

Wilms: Zent. f. Chir., band xxxi, s. 633 .

Mosher, H. P.: Boston Mrdical and Surgical Journat, v. clxvi, No. 4 , pp. 84,85 .

Greene, D. C.: Boston Medicat and Surgical Jocrnal, v. cxlviii, No. 18, p. 470 .

\section{Jel $\mathfrak{F}$ ingtrument.}

\section{A NEW URETHRAL IRRIGATOR.}

BY F. J. COTTON, M.D., Boston, Assistant Surgeon, Boston City Hospital;
Department, Boston Dispensary.

The more we come to appreciate the value of thorough irrigations in urethral treatment, the more important it becomes to have the best and handiest means of carrying them out. There is no lack of irrigating devices, some of them very handy. Practically all of them, properly handled, are efficient; most of them have obvious, if not important, defects. In venturing to present a new type of irrigator nozzle, I can only say that it avoids some of the defects present in the usual models, is handy, cleanly, readily sterilized, and cheap.

Irrigations to be of value must first of all be so managed as to give thorough washing. This means a large quantity of irrigating fluid, preferably so introduced as to cleanse the urethra progressively from the entrance backward, and so handled as to give a constant or intermittent distention of the canal, so that fluid is brought in contact with the whole surface. This has been carried out in various ways. Irrigation by catheter is an undesirable method, for whether done with a stiff, olive-pointed instrument with retrograde out-flow, or with a simple glass or soft rubber catheter, it entails in any case a trauma of the mucous membrane which may not be great, but is wholly undesirable. The method 